\title{
THE READER, THE TEXT, THE CONTEXT: AN EXPLORATION OF A CHOREOGRAPHED RESPONSE TO LITERATURE
}

\author{
Peter Smagorinsky and John Coppock \\ University of Oklahoma
}

\begin{abstract}
Much current theory about response to literature stresses the reader's active role in constructing meaning, with reader, text, and context affecting the responses of individual readers (Beach, 1993). Response to literature, like most classroom interaction, tends to take a linguistic form. In a supportive classroom environment, however, a range of response media can potentially mediate students' transactions with literature. The present exploratory study used stimulated recall to elicit a retrospective account from two alternative school students who choreographed a dance to depict their understanding of the relationship between the two central characters in a short story. In their account they indicate that in composing their text they (a) initiated their interpretation by empathizing with the characters, (b) represented the characters' relationship through spatial images and configurations, and (c) used the psychological tool of dance to both represent and develop their thinking about the story. Their thought and activity were further mediated by the social context of learning, including the communication genres of the classroom, their own interaction, their teacher's intervention, and the stimulated recall interview itself. Their account illustrates the way in which reader, text, and context participate in a complex transaction when readers construct meaning for literature. Their experience also illustrates the ways in which the values of an instructional setting influence the extent to which learners may take advantage of the psychological tools available to them for growth.
\end{abstract}

$Q$ : What kinds of decisions do you have to make in artistic dance?

Jane: What all you can do, what can you work with. It's like you can't work with any props or costumes. All you have to do is work with your body and that 
is pretty much what dance is except usually when it is a big suite or a ballet they have costume and props. You have to work with yourself. You have to make sure that you know the story line by line, and we also have to be able to work together as a team. If there is more than one person, it does take teamwork because otherwise people are in competition with each other to get the better part and all of that stuff and I've been in that situation before. And we had to talk about what all we could do to symbolize stuff because that's what [our teacher] loves.

This account of the potential of dance for enabling learners to construct and represent meaning comes from an interview with two young women enrolled in an alternative high school for recovering substance abusers. The questions that elicited their account were stimulated by a videotape of the students as they choreographed a dance to represent their understanding of the relationship between the two central characters in a short story. Their account revealed that through the planning and practice of their dance, they reconstructed the events of the story into a new text of their own. This reconstructive process came out of the transaction they experienced between their own personal experiences and the ways in which they read the signs of the literary text. In addition, the process of composing their choreographed interpretative text changed their understanding of the conflict in the story they had read.

In this report we investigate the processes engaged in by the dancers as they worked out a choreographed interpretation of the story. Our analysis focuses on the process of "transmediation" (Harste, 1993; Suhor, 1984); that is, the manner in which the students read the signs of the literary text, collaborated on the construction of meaning for those signs, and created a new representation of that meaning through a different sign system. Typically, meaning construction is mediated by linguistic tools such as writing (e.g., the response journals described by Hancock, 1993). Our investigation of literary response through alternative sign systems suggests that the effectiveness of a particular psychological tool-writing, dance, sculpture-is dependent on the cultural appropriateness of that tool in terms of both the learner's personal background and the values of the instructional environment (Smagorinsky \& Coppock, 1994a, 1994b, in press; Wertsch, 1991). The potential of a mediational tool such as dance, therefore, comes in part through the inherent capacities of the tool itself and in part through the ways in which the social environment of production values the appropriateness of the tool and the different ways of using it.

Our research was designed to explore several questions:

1. In what (admittedly idiosyncratic) ways do students construct meaning in response to the written signs of a literary text? (See Bloome \& Bailey, 1992, for a rationale for studying the particular rather than the general.)

2. What unique properties of a selected interpretive medium-in this case, danceenable individual students to use it as viable mediational tool? 
3. How does the social context of learning influence the degree to which a learner uses mediational tools in profitable ways?

Our framework for accounting for students' construction of a meaningful interpretive text is rooted in Peirce's (1931-1935) semiotic theory that postulates a triadic relationship among object, sign, and interpretant (cf. Witte, 1992). Nystrand's $(1986,1989)$ social-interactive model of writing illustrates the ways in which this triadic relationship is manifested in readers' construction of meaning from written texts. In Nystrand's model:

the meaning of any text is neither (a) found in the writer's intentions, which, according to cognitive models of writing, the writer "translates" into text, nor (b) embodied in the text itself, as proposed in such formalist accounts of exposition as Olson's (1977) doctrine of autonomous text. Rather, texts are said merely to have a potential for meaning, which is realized only in use, for example, when a text is read (even by the writer). This meaning is dynamic, which is to say, it evolves over the course of reading ...; it is not exactly the same from reader to reader; and it manifests the cultural and ideational assumptions readers bring to the text. This is not to say that readers completely determine the meaning of the text; instead, whatever meaning is achieved is a unique configuration and interaction of what both writer and reader bring to the text. (Nystrand, Greene, \& Wiemelt, 1993, pp. 298-299)

A semiotic social-interactive perspective therefore views the act of reading as a transaction between reader and text, with both the reader's history and the context of reading informing and influencing the associations the reader makes with the signs of the text. All three of these factors-the reader, the text, the context-are conjoined in the construction of meaning during a literary transaction (Rosenblatt, 1978).

The concept of "meaning," although often invoked in discussions of learning, is rarely defined. Smagorinsky (1986; 1995; Smagorinsky \& Coppock, 1994a) has argued that meaning construction involves a personal transformation through goaldirected, tool-mediated social activity that serves a developmental purpose in the production and interpretation of semiotic signs. Such tool use can potentially put a learner in the "flow" of learning (Csikszentmihalyi \& Larson, 1984), which is a state in which a person reaches new stages of complexity through action that is intentional, intrinsically motivated, and autotelic, and that involves similar degrees of challenge and skill.

The context of reading is a significant factor in our conception of meaning construction (Chin, 1994). The context of reading includes both cultural and social factors. Hull and Rose (1990) argue that students' cultural backgrounds can inform their interpretations of literature in ways that at times seem "unusual, a little off, not on the mark" (p. 287) and therefore illogical to teachers. In addition to the students' cultural backgrounds, the social climate of the classroom can affect students' ways of thinking about literature. Teachers frequently control classroom 
discourse, for instance, in ways that circumscribe students' ways of approaching literature (Marshall, Smagorinsky, \& Smith, 1995; Smagorinsky \& Fly, 1993).

Our analysis of a choreographed response to literature takes into account the unique classroom environment within the alternative school and the ways in which the teacher and students valued unconventional means of constructing meaning. Most response to literature in public schools is spoken or written (Applebee, 1993). The privileged status of linguistic expression is evident in Vygotsky's (1987) identification of word meaning as the appropriate unit of analysis in psychological research. To Vygotsky a unit of analysis is a focal product that retains all of the basic properties of the whole and thus serves as a microcosm for the dynamic interfuctional organization of consciousness. In Vygotsky's view thinking and speech are the keys to understanding consciousness, with word meaning serving to represent the workings of the mind:

Consciousness is reflected in the word, as the sun is reflected in a droplet of water. The word is related to consciousness as a miniature world is related to a large one, as a living cell is related to an organism, as an atom to the cosmos. It is a miniature world of consciousness. The meaningful word is a microcosm of human consciousness. (quoted in Wertsch, 1985, p. 194; original quote in Vygotsky, 1934, p. 318)

Yet written or spoken language is but one sign system capable of mediating a reader's response to literature. Beach (1993) identifies a "steadily widening range of response media, including, for example, oral interpretation, role-playing, artwork, rewriting texts, or creating new ones" (p. 6; cf. Smagorinsky, 1991, 1992; Smagorinsky \& Coppock, 1994a, 1994b, in press). Providing students with multiple means of response is consistent with the sociocultural perspective on schooling that motivates the work of Nystrand et al. (1993). Wertsch (1991), who like Nystrand draws heavily on the work of Bakhtin and Vygotsky, has argued that educators should value "the diversity of mediational means available to human beings" (p. 93) and consider a "tool kit approach" (p. 94) to schooling that allows for differences in the ways in which individuals and cultural groups make meaning. "Some tools are more powerful and efficacious for certain activities or spheres of life, and others are more powerful and efficacious for others," argues Wertsch (p. 102). By allowing students to use a "tool kit" he means that instead of focusing on-or "privileging"-one type of cultural tool such as writing as having a special capacity for making meaning, educators should consider a range of media through which students can express themselves, thus allowing more flexibility in the types of tools students use in classrooms.

Yet simply giving students "tool kits" for constructing meaning is not sufficient, for tools are only effective in environments that value their use. Wertsch (1990; cf. Ackerman, 1993) has argued that in order to understand the role of cultural tools in the construction of meaning, psychologists interested in a sociocultural approach must analyze institutional and cultural factors to account for 
why particular tools are and are not valued in particular settings. Our analysis of dance as a psychological tool for mediating students' response to literature is thus inextricably linked to the context of our investigation; a "widening range of response media" (Beach, 1993, p. 6) is valuable only when an instructional environment encourages their use as tools for constructing meaning.

\section{CONTEXT OF THE INVESTIGATION}

\section{The Facility}

The research took place in a residential drug and alcohol rehabilitation facility that provided both therapy for recovery and public school educational classes. The students had committed themselves (sometimes reluctantly) to therapeutic, community-based treatment for 6 to 18 months. Because of federal and state laws related to confidentiality, no information that links data, location, and specific identities of individuals may be described or suggested. The names of the students focused on in this report are pseudonyms, and confidentiality agreements prevent us from reporting their specific academic records prior to enrolling in the facility.

A general description of the facility is possible, however. The setting for the research was an important factor in the students' recognition of artistic texts as legitimate social and intellectual expressions. The students lived at the facility, which was located in an isolated, rural community. Although the students could not leave the grounds without supervision, inside the facility they were entrusted with many responsibilities. Students were accountable for all aspects of daily maintenance and therefore cooked for each other and cleaned up after one another. As part of their recovery from their addiction they were engaged in daily formal therapy that extended to their social transactions. To aid recovery students needed to have a great deal of trust in one another and to support each other emotionally. Hugging, walking arm-in-arm, and otherwise displaying physical concern and support were common, regardless of gender; sexual contact, however, called for expulsion. Students could only be accepted into the program by a vote of the other residents following a trial period.

\section{The Students}

This report focuses on two young women, "Jane" and "Martha." Jane was enrolled as a junior and Martha as a sophomore. Prior to enrolling in the facility, both had exhibited a discrepancy between language ability and grades in language arts classes. Their main areas of success in mainstream schools had been in the arts (art, music, drama). After enrolling in the facility, they both received high grades in their respective language arts classes.

Jane was a 16-year-old white female. Her scholastic standing was normal for 
her age. Jane reported that she was an experienced dancer, having been involved with dance for 4 years:

I can do dance easier [than Martha]. ... [In choreographing the dance] I wrote down some steps like the shasha too, I learned those. See I have never taken ballet, but my stepmother had and she would teach me things, and my jazz teacher, because there was only two people in her class and she would teach me this special stuff. It was real fun. It is fun to mix all of the little dances together and have like your own little brand of dance because you have modern jazz and tap and ballet and all of this stuff just thrown in.

Martha was a 15-year-old Native American who was enrolled as a sophomore. Her teacher reported that she had often revealed a great insecurity, such as when she repeatedly requested information about her I.Q. even though tests placed her at the 12th-grade level in reading comprehension and mathematics. Prior to arriving at the treatment center, she had limited experience with dance, with that experience being recreational: "two step and cotton eyed joe country dance, things like that." She began dancing more seriously when she made friends with Jane at the facility. Martha did not consider herself to be a dancer: "See I am not really much of a dancer. I am more of a writer than a dancer. [When we were dancing] most of the time I just followed [Jane]." Martha's tendency to follow Jane was, according to their teacher, typical of their relationship. Jane was the older of the two and was more outgoing and somewhat dominant in their relationship.

Jane and Martha had entered the treatment center 1 day apart and had both been enrolled for about 2 months at the time of the data collection. Normally, Jane and Martha were not in the same class at the facility, being at different grade levels; they had developed their friendship through other activities at the facility. They chose to work together in their interpretation because of their artistic and emotional compatibility. During the stimulated recall interview the following exchange took place:

Jane: This girl is the most creative girl I ever knew and I knew she could do [the dance]. Whenever we have meditation groups it is like I can tell what she says about her meditation. Like you said it is real easy for me to read people. There is some people in there that I know cannot dance, cannot keep their balance, cannot do this and do that and that is why I dance with Martha. A lot of people are ticked off because I didn't want them to be in my dance. It isn't my fault but it's just that I had to find somebody that could keep balance and that I could get along with, would agree with, or at least talk about certain things I said. A lot of people in here will not do that. They have to have it their way.

$Q: \quad$ Do you think that is one reason you two get along so well?

Jane: Yeah.

Martha: We have a lot of similar background, same issues. So we're able to talk to each other and compromise and get things worked out.

Jane: We understand each other better than anybody else.

Martha: Even when we're working on a project and she comes up to me and I 
say I'm pissed off, I'm pissed off and we sit down and talk about it. We can sit down and talk about it. It's been easy for us ever since I first got here. We can sit down and talk about it. It's real easy for us to do that. Jane: See when she first got here we didn't get along at all, but then when she started opening up you know and ever since then we have been real close friends. Real, real close friends. Like she is the only person I have trusted in here to listen to me and so when I asked her to do this dance I knew she wouldn't make fun of me. There is a lot of people who make fun of you around here.

Their sharing of "issues" in the intensely therapeutic environment of the substance abuse treatment center, then, helped to bring them together in friendship, a factor that influenced their decision to work together on their response to the short story.

\section{Instructional Context}

Teacher's characteristics. The teacher of the classroom analyzed in this report had taught for a total of 15 years in public secondary schools, interrupted by a 7year hiatus to manage a family-owned piano and organ business which he continued to preside over when he resumed teaching. The teacher was a published poet and had been writing poetry for 30 years. Though not a formal performer of arts or music himself, his family of origin had been extensively involved in the arts: His mother had been a painter and ceramic artist, his sister had trained as a concert pianist, and his brother had been a professional dancer and choreographer.

The teacher's graduate education had brought him into contact with the work of Howard Gardner (1983), whose theory of multiple intelligences stresses the potential for expression through spatial, musical, bodily/kinesthetic, interpersonal, and intrapersonal intelligences in addition to the mathematical/logical and linguistic intelligences typically assessed in schools. Gardner's theory had helped the teacher account for his own experiences with creativity.

Communication genres. The facility employed only two teachers, each of whom taught a variety of subjects, enabling their instruction to cross disciplines easily. The teacher was obligated to cover certain amounts of material in each discipline but had unusual flexibility in the ways in which he could teach the subject matter. By the end of the second month of the year-the time of the data collection-the students were familiar with an environment that validated a variety of communication genres, a term we use to describe a broadened version of what Bakhtin (1986) calls "speech genres."

Speech genres describe an appropriate grammar and terminology, and also "specify regular sequencing of types of action, of the functional constituents of an overall activity [such as] the question-answer-evaluation dialogue of classrooms" (Lemke, 1988, p. 82). The ability to adapt to the linguistic conventions predominating particular contexts affects one's success in those contexts, maintains Wertsch (1991): "socialization involves mastering the rules for using particular speech genres 
in particular sociocultural settings" (p. 130). In the context of the present discussion the concept of genre refers to the distinctive characteristics of communication in particular environments, regardless of the medium. Thus the term communication genre would more appropriately describe the conventions governing appropriate expression when students use a "tool kit" of mediational means (Wertsch, 1991). In Jane and Martha's class, students were encouraged to participate through a variety of communication genres as they constructed meaning in and across the various disciplines.

Prior instruction. Prior to the data collection students had a series of experiences with artistic response to literature similar to that studied through the stimulated recall interviews. In each case they were asked to create a product of their choice to represent their understanding of or response to a given text; students were given the option of working alone or with peers. The students responded to two stories and two slide projections of paintings prior to the data collection. The teacher's goal with this sequence of instruction was for the students to be able to read, visualize, and respond to stories independent of teacher direction, though quite possibly through collaboration with other students.

\section{METHOD}

\section{Data Collection}

General procedure. The research employed "stimulated recall," a methodology originally developed by Bloom (1954; cf. Rose, 1984, and DiPardo, 1994) to study students' thought processes during classroom discussions and lectures. Bloom filmed students during discussions and lectures and immediately used the film as a stimulus for a retrospective account describing thought processes during the class period. He developed the methodology to identify thought process and levels of attention without interrupting the classes or processes themselves.

In a stimulated recall interview the researcher should be considered as a coconstructor of the data rather than as a neutral factor. "Neutral" behavior in interviews is at best an illusion (Rosenthal, 1966; Smagorinsky, 1994). Researchers using various methodologies are accustomed to questioning the extent to which their presence "contaminates" the data. Yet in interviews the data are socially constructed; they are never "pure" to begin with (Smagorinsky, in press). In a stimulated recall interview the researcher prompts the participant's reflection in areas that are within grasp yet might not otherwise be reached. Even when the researcher attempts to avoid cueing particular responses, the prompts and questions help to shape the substance of the verbal text provided by the participant.

The methodology complicates the data analysis in a crucial way. Most stimulated recall studies (i.e., Bloom, 1954; Rose, 1984) have attempted to reconstruct 
thought processes with the assumption that the account of process yielded in the interview represents a reasonably accurate report of a prior pattern of thought. Two factors, however, make it unlikely that the account is a precise rendering of a prior thought process. In the research we are presently reporting, the interviewer's participation introduced a new voice in Jane and Martha's consideration of their dance that had not affected their thinking during their planning of the choreography. The interviewer's questions likely mediated their perspective on the choreographed text they had previously created. The interview, therefore, could have caused them to interpret their text in ways not possible in their prior considerations of the story and of the dance through which they interpreted it.

The second issue is that the interviewer's questions could well have helped produce a new text for Jane and Martha. In other words, their original production of the dance may have had a particular meaning to them that the dialogue of the interview mediated into a new understanding. We are less confident, then, that the interview produced an accurate record of prior thought processes than that it generated further development of their interpretation of their own choreographed text and the story that had inspired it, a consideration that no doubt continued beyond the bounds of the data collection as they continued to think and talk about the story and their dance.

\section{Procedures for this Study}

Videotaping procedures. The data were collected on 2 consecutive days at the end of the second month of the school year. On the first day the classroom was set up in its normal arrangement, which seated students at a loose collection of small tables each accommodating four to five chairs, plus additional chairs and a couch. Normally, the students were divided into two classes of 17 students, but on this day the classes were combined so that all students in the facility participated in the activity.

In two adjacent corners of the room, video cameras were angled at 45 degrees so that every point in the room was filmed by either or both cameras. Students were given individual photocopies of a short story, William Carlos Williams's "The Use of Force." The story concerns a doctor who narrates an account of a house call he makes during a diphtheria epidemic. The doctor must extract a throat culture from a young girl who has displayed symptoms of the illness. The girl battles him savagely and hysterically to prevent him from examining her throat, and her parents try to help the doctor by holding her down and shaming her into complying. During the course of the struggle the doctor develops contempt for the parents and passion towards the girl. Against his rational judgment, the doctor becomes lost in "a blind fury" to attack and subdue the girl. In "a final unreasoning assault" he overpowers her and discovers her "secret" of "tonsils covered with membrane." The story ends with a final act of fury in which the girl attacks the doctor "while tears of defeat blinded her eyes." 
The teacher wrote the following instructions on the chalk board:
A. Read the story individually or with co-workers using some method to reach an understanding of the story.
B. Create some product that can communicate your understanding.
Check your product:
Do "I" personally, like the product?
Do "I" see ways I would perfect it later?
Do "I" see ways I could have it better later?

In addition the teacher provided a definition of "diphtheria."

The room had been stocked with a variety of media through which the students could express themselves: conventional paper and pens for writing, tinker toys, paints and other art supplies, a versatile keyboard synthesizer, a simpler keyboard instrument, and a computer with a graphics program. In addition, some students went to their rooms and got guitars, cassette music tapes, masks, and other resources to supplement what had been provided for them.

The students had a total of 1 hour in which to read the story, decide how and with whom they would respond to the story, and produce their texts. The video cameras filmed the entire hour, including the reading of the story.

Following the teacher's presentation of the assignment, he circulated around the room throughout the class period to answer students' questions about the assignment and their productions. He acted as a resource for students during their activity, both for clarifying the instructions he had given and for providing assistance and feedback to students on the particular questions they had on their own productions.

Stimulated recall interview. This report focuses on Jane and Martha's choreographed response to the story. The interview with Jane and Martha took place the day after the class session that had been videotaped. The researcher had viewed the videotape once prior to the interview session, although with a focus on a different student (Smagorinsky \& Coppock, 1994a, 1994b). Jane and Martha sat with the researcher in front of a large television screen to view the videotape of their reading and choreography of the dance. As the videotape played, a portable audiocassette tape recorder recorded the interview between researcher and students. The researcher's questions were not preplanned but were stimulated by the activity on the videotape or by remarks made by Jane and Martha that the researcher prompted for elaboration. The researcher's role, therefore, was to use the videotape to pose open-ended questions requesting retrospection about the thought processes behind particular behaviors. Of course, the researcher's choice of questions was influenced by the perspective that had originally motivated the research, and we would be disingenuous to claim that we had no prior sense of how the students might account for their composing activity or no notion of what sorts of questions might elicit that account. Nonetheless, the interviewer made an effort to let the videotape stimulate the retrospective account provided by the students. Examples of the ques- 
tions and prompts of the interviewer appear throughout the transcripts reported in the results section of this report.

\section{Unit of Analysis}

The data base for the research was the transcript of the interview in which Jane and Martha responded to the videotape to discuss their process of production. The interview, although stimulated by the images on the television screen, also ranged outside the bounds of the video. For instance, at one point Martha used the hall pass to go to her room to get a tape of The Nutcracker and during this point the interview shifted to Jane's prior experiences with dance. Throughout the interview Jane and Martha talked about the processes they had gone through in reading the story, determining their medium of response, discussing their response to the story, and planning and practicing their dance. These processes were recursive.

We have not included an analysis of the dance itself for two reasons. First of all, from a theoretical standpoint, the dance itself is not a suitable unit of analysis. Wertsch (1985) has criticized Vygotsky's (1934/1987) view that word meaning should be the unit of analysis for studying human consciousness, arguing instead that words mediate the units of analysis, rather than being units of analysis themselves (cf. Zinchenko, 1985). In other words, the psychological tool-for Vygotsky, speech; for us, dance-mediates between the activity of consciousness and the material context which it mutually acts upon and is acted upon by. To Wertsch, the appropriate unit of activity is goal-directed, tool-mediated action (pp. 199-208). The appropriate unit of analysis in the present study, then, is not the dance itself but the psychological functioning mediated through the dance; our access to this mentation is the account elicited by the stimulated recall interview. The dance is not irrelevant; indeed, we are looking at how the psychological tool of dance acts as a means of mediation and therefore how it simultaneously represents and shapes consciousness. The psychological activity that created the dance-at least, the extent of activity available through the stimulated recall interview with all its potential mediational influence-and not the final form of the product, is our focus of study.

The second reason we do not analyze the product of the dance concerns the way in which the research was situated within the structure of life at the treatment facility. As part of their rehabilitation, the students' lives were heavily scheduled. They had to attend therapy sessions, prepare meals, and participate in work duty to maintain the facility. The research was designed to be as unobtrusive and respectful of the students and their rehabilitation as possible, and the research was conducted so as not to upset the priorities of the program. We therefore did not "design" a study at the facility so much as capture an instructional episode that took place within the confines of the schedule. The time allotted for the activity (1 hour) allowed for a reading and discussion of the story, and then the planning and practice of a dance, rather than the development of a polished, analyzable performance. 
Jane and Martha therefore did not arrive at a fully finished product. The analysis thus centers on a stimulated, retrospective account of their thoughts as they planned a dance that they would perform at a later time. Our focus was on the process of response, rather than on making judgments about the quality of the finished dance. In our view, the actual quality of the dance as judged by a dance expert-a subjective judgment that would no doubt vary depending on the criteria applied-was less important than the dancers' account of the processes involved.

Following is an account of the visible vestiges of the planning and practice of the dance as made available by the videotape that stimulated the interview: Jane and Martha were seated at a table in the middle of the classroom. The teacher took about 5 minutes to explain the assignment, following which the students read quietly for 11-14 minutes. Jane finished first and began talking with the male student sitting next to her, who began to gesture vigorously with his hands. Martha then finished and joined in, with the teacher stopping by to answer the male's question. During the discussion the three students gestured towards their mouths and posed with their mouths open wide. Jane and Martha came close together and talked and gestured, after which Jane began making notes on a paper. They paused and conferred with frequent gestures towards their mouths. The teacher stopped by and the male then left to work with tinker toys. Jane and Martha raised their hands for the teacher's attention but he was engaged with other students. Finally they got his attention and he spoke with them. Martha left the picture and Jane began writing notes. Martha returned and looked at the notes and they gestured with their heads. They again called for the teacher and requested permission to get something and to practice in privacy; the teacher granted permission. Martha left to discuss borrowing a tape of music from another student. When Martha returned they spoke and Jane drew lines on her notes. They talked to their teacher again and then pivoted their heads, huddled down, and opened up again. Jane then drew circular lines on her notes. Martha gestured with her arms in waves and circles and Jane motioned to a spot and the two then made rhythmic motions. The teacher then gave them permission to play music (not all students at the facility were allowed to use electronic equipment) and Martha went to get a tape. Jane made additional notes while waiting. Martha returned with a tape and then left to get a tape recorder. When she returned Jane and Martha left the room briefly to practice in the gymnasium adjacent to the classroom. The teacher left the classroom one time to check on their progress.

\section{Data Analysis Procedures}

The interview with Jane and Martha produced a 22-page transcript which we subjected to analysis. Transcripts of protocol data (concurrent or retrospective) are amenable to the development and application of different coding systems depending on the confluence of the theoretical perspective that motivates the analysis and 
the substance of the data themselves (Smagorinsky, 1994). We viewed the activity of Jane and Martha through a sociocultural perspective based primarily on Wertsch's (1985, 1991) and Moll's (1990) appropriations of Vygotsky and Bakhtin; that is, we saw their activity as culturally situated in the context of the alternative school, with the physical, instructional, and emotional context of production enabling them to employ their choice of psychological tools for the construction of meaning in both their interpretation and creation of literary and artistic texts. We found that Gardner's $(1983,1993)$ theory of multiple intelligences complemented this perspective well with its legitimation of artistic meaning construction and expression and its semiotic implications. This perspective provided us with concept-driven discourse for accounting for the processes elicited through the interview.

Following multiple readings of the transcript and discussions of possible coding categories that emerged through a conjunction of the motivating theories and the material provided in the interview, we identified categories to account for the significance of each statement in the transcript. The categories we identified were as follows:

Empathizing with characters. When the speaker would indicate feeling for or connection with a character from the story. Example: "It is like you are saying you have to put yourself in their position. When you read the story it tells, it is like in between the lines, it tells how the doctor feels about the girl, and it tells how the little girl feels."

Representing Meaning through Kinesthetic and Spatial Relations:

Visualizing images. When the speaker would describe how she would create mental images to aid in the conception or performance of the dance. Example: "We did leaps and she was trying to, she couldn't do it because she kept trying to do it with the foot that she was stepping on and I would say, "Act like you are about to jump over a little pond,' and she would do it."

Representing characters through physical symbolization. When the speaker would describe the ways in which the spatial relations of the dancers represented an interpretation of the story. Example: "It is like at the very end they walked together. It's like they walk two steps and when you do a little pause, the doctor shelters her and just looks at her because he's died with her, his whole life has just gone down the drain because it's another kid, he feels it's all his fault this time."

Mediating function of the social context of learning. When the speaker would refer to the manner in which the context of learning influenced her thinking. Example: "[Our teacher] has got this brilliant mind. He can think of things you could never even see in an art book. Even in our dance he sees things we didn't mean to do. We were dancing, he came in there and said 'this and this and this.' He took it deeper than we did." 
Basis for collaboration. When the speaker would explain the reasons for the decision to collaborate. Example: "... we have a lot of things in common, she can act real well, she can dance real well and we like most of the same things."

Selection of music. When the speaker would refer to the process of selecting the music that would accompany the choreography. Example: "We picked out music that [followed the plot of the story] and it was real soft and it had those voices like the people sing. Have you seen Flowers in the Attic?" [Q: "No."] "It is like the voices that go mmmmmmm [hums tune] like that, real soft, the music sounds real beautiful, real eerie. It goes real slow at first and then it gets up into a rage. And then at the very end you hear the cymbal crash and it goes down."

Selection of medium. When the speaker would refer to the choice of representational medium. Example: "I had already thought I was going to do a play and then me and Martha started talking about it, and we changed our minds."

Literal description of videotape. When the speaker would describe an action on the videotape, without elaborating. Example: "Martha's talking."

Prior experiences. When the speaker would refer to an activity or experience that had occurred prior to the action on the videotape. Example: "I have never taken ballet, but my stepmother had and she would teach me things, and my jazz teacher, because there was only two people in her class and she would teach me this special stuff."

"Drafting" of choreography. When the speaker would describe the ways in which ideas were tried out and then revised. Example: "You can't really sit down and say, 'Well, what steps am I going to do?' You have got to get out there and try different steps to do it. To see what you fit together. Because if you just think about it, trust me, nothing is going to fit."

Emotional potential of dance. When the speaker would describe the ways in which dancing served as a medium for expressing emotion. Example: "Ballet is kind of a sad dance for me but yesterday it was like different. It gave me enjoyment, it gave me a lot of self-esteem."

Following the development of the coding system, we coded each segment (usually consisting of one sentence) in the transcript according to the categories. (See Table 1 for the categories and frequencies with which they appeared in the transcript.) The process was not entirely insular; that is, the process was not intended to provide a circular theory verification with no consideration of other possible interpretations of the data. Our discussions about the transcripts cycled us through a number of possible ways to code the data, each emerging from a variation on sociocultural theory. Our final decisions came through a careful consideration of what the data provided us with and how we viewed them, and the ultimate codes were developed in order to provide congruence between the data analysis and the theory that we saw as best accounting for the processes in question. 
Table 1

\section{Coding Categories}

Empathizing with characters

Representing Meaning through Kinesthetic and Spatial Relations

Visualizing Images

Representing Characters through Physical Symbolization

Mediating Function of the Social Context of Learning

References by students

Questions during Interview

Basis for Collaboration

Selection of Music

Selection of Medium

Literal Description of videotape

Prior Experiences

"Drafting" of Choreography

Emotional Potential of Dance

We decided that some of the statements from the transcript would be best deployed in providing contextual information about the dancers; their prior experiences, basis for collaboration, and their account of the emotional potential of dance appear outside the "interpretations" portion of this report. We then chose to focus on the most frequently reported processes in the transcripts for our account of their choreographed interpretation of the story.

By the time the data analysis was finished, Jane and Martha had graduated from the facility and were unavailable to confirm the validity of the analysis. Efforts to contact them were not successful.

\section{Limitations}

Before proceeding we should acknowledge the limitations of this research. In describing an exploratory study investigating the responses of two students to a single story, we are not representing this work as conclusive or labeling our results as "findings"; indeed, we have chosen to use the term "Interpretations" rather than the conventional "Results" to describe the content and analysis of the interview data to make explicit the tentative nature of our investigation. As noted, we see our "results" as being reconstructed texts of reconstructed texts; Jane's and Martha's processes of transmediation went from a reading of a textually configured set of linguistic signs, to a reconstruction of those signs through the collaborative creation of choreographed signs (configured spatially and representing specific cultural codes), through a verbal reconstruction of that choreographed text mediated by attention to a visual representation of the dance on video and stimulated by the prompts of a third party's questions about that representation. 
Yet this very developmental process of transmediation illustrates much about the theory that we find instrumental in accounting for the reading behavior of the learners. We offer this account-and in turn our interpretation of it, mediated extensively by our discussions as coauthors, our reading of theoretical texts, and our copious interaction both with colleagues and with the editors and external reviewers of $J R B$ over how to analyze and represent it-as illustrative of the processes of transmediation, particularly as they take place in an environment that values the use of psychological tools that are situationally appropriate to students and their developmental needs. In essence, we see this analysis of transmediation as a detailed study of the extended processes of development (including development through the investigative process) experienced by two students as they engaged in an interpretive production within the communication genres available in the instructional setting (with the researcher's mediation included in that setting), processes that in turn helped to define the boundaries of those genres.

\section{INTERPRETATIONS}

Our sociocultural semiotic perspective focuses on the ways in which readers attribute meaning to the signs of the text, with their own personal and cultural histories informing their process of meaning-making and the social environment of reading affecting the medium and shape of their response. The stimulated recall account provided by Jane and Martha illustrates the process of meaning-construction they engaged in when, in the supportive context of the alternative school classroom, they used the cultural tool of dance to mediate their understanding of a short story assigned by their teacher.

In describing the process of choreographing their dance, Jane and Martha revealed three processes central to their transmediation. First of all, they reported that they initiated their response to the story by empathizing with the literary characters. Second, they described the employment of both spatial and bodily/kinesthetic intelligences to (a) visualize appropriate images to inspire their portrayal of the characters and (b) represent the relationship between the characters through their positioning relative to one another. Third, they revealed that in engaging in these processes, they produced a composition that served a dialectic function: Their thinking about the signs of the literary text both shaped and was shaped by the process of choreographing and performing their dance. Furthermore, their choreographed text was likely mediated by the social context of learning, including the communication genres valued in the classroom, their interaction during the production of the dance, the intervention of their teacher, and the process of participating in the stimulated recall interview itself. Their choice of the medium of dance to interpret the story reflected Jane's personal history of using dance to express emotion, and Jane and Martha's shared history of friendship, therapy, and personal 
exploration. It also reflected the breadth of the communication genres sanctioned in their classroom at the treatment center. As Hanna (1987) has argued, "dance is essentially meaningful in its sociocultural context" (p. 19); Jane and Martha's decision to use dance as an interpretive tool came through their teacher's recognition of the value of unconventional response media in academic meaning construction.

The following sections illustrate each process with excerpts from the interview.

\section{Empathizing with Characters}

Jane and Martha chose to represent their understanding of the story through the vehicle of dance in large part because of its potential for emotional expression. Hanna (1987) has observed that "Like other cultural codes and patterned interactions, dance is a way of ordering and categorizing experience: it may even be that statements made in the dance form cannot be made in another" (p. 25). This affective dimension of dance influenced Jane and Martha's decision to choreograph their interpretation of the story. Jane had originally wanted to perform a play to depict their understanding of the story but then changed the medium to dance: "In the dance you can show more emotion than you can in a play. I dance all the time. That is how I show emotion. ... Ballet is kind of a sad dance for me but yesterday it was like different. It gave me enjoyment, it gave me a lot of self-esteem." Selfesteem, as one might expect, was a recurrent issue in the therapy that was central to the students' rehabilitation at the facility.

The potential of dance for enabling emotional expression revealed itself through Jane and Martha's empathic connections to the literary characters. Martha said that she identified strongly with the experience of the girl in the story because she shared the character's reluctance to open up to other people. Like the girl in the story, she felt "scared": "I felt like the little girl because we live in two different worlds.... I felt like the little girl because she was always trying to hide from the doctor and I was like hiding myself from the doctor." Martha's feeling that she needed to hide from the doctor stemmed from experiences parallel to those of the girl in the story. At one point she was asked, "When you dance a role, do you, is there any real part of you that gets played out in the dancer?" Martha replied:

Martha: It's tough for me. When I was hiding from [Jane in the dance] she was the doctor and I was the daughter, the little girl, and it was just like me. I hate people trying to find out who I am so I was basically hiding the way I always hide but I was hiding to be somebody else. I felt like I was hiding in the little girl, but it was me that was hiding, because I do that all the time. I hide from everybody.

$Q: \quad$ Did you feel for the character then?

Martha: Oh yeah, I felt for the character. When I was dancing I was thinking about what I would do. I hated what the doctor did to her. I wanted to kill him. 
Later in the interview Martha returned to her feelings about her character:

Martha: My feelings for the kid started when I was reading the story because there have been many times when I have had some problems. I' $\mathrm{m}$ like I'm okay, get away. In a way I kind of knew how this girl was feeling whenever the doctor was trying to get into her mouth. I am like that with dentists. I hate dentists. I won't let them get into my mouth. I'm afraid they're going to pull out my teeth. It scares me. I try to keep my mouth shut too. I put myself in her position through the whole story knowing she was scared and very insecure because she knows she is going to die. She knows through the whole story she's going to die. She doesn't want her parents to know about it.

$Q: \quad$ Is it just dentists? Earlier you were talking about how you don't like people in general getting inside you. So was it just a dentist or was it-

Martha: Well, for people to know me, I don't like for anyone to know me, it is really scary for people to know me. Who I am or anything like doctors, and stuff like that. I don't like them to look inside my mouth. With her I feel like she doesn't want the doctor to know she is dying because I am pretty sure because she could feel her tonsils. She knows she is dying. She knew it, she knew it was there and she knew she was going to die and she didn't want her mom to know. She didn't want her parents to know.

Martha's personal connection enabled her to understand the character and informed her portrayal of the girl in the dance. Her remarks reveal that through her empathy for the sick girl, she drew on deeply personal knowledge of the sort of conflict experienced by the character and therefore infused her portrayal with meaning. Her account of her process illustrates the "interinanimation" that Rosenblatt (1978) finds in literary transactions, where the signs of a text prompt associations with the reader, who in turn constructs meaning for the signs. Her own interpretive text-the dance-then became a construction of her own in response to the signs offered by the literary text.

Similarly, Jane's sense of connection to the doctor enabled her to perform his role:

I was sitting there trying to figure out who [Martha] is and I do that in everyday life. Like I can look in somebody's face and figure out what is going on. I mean I can't read minds, but I can look in someone's face and I can read expressions real well and attitudes real well. I can tell what issues they are probably dealing with and how they feel about it. And it is like I was trying to figure her out through the whole dance. And that is why the doctor was a great role for me, even though I do hide from people too. I think the doctor was a better role for me.

Jane's disposition to read people's feelings enabled her to play the role of the doctor through her understanding of the feelings of both characters. Like the doctor she attempted to "read" the girl's feelings in order to proceed with her diagnosis. With Martha embodying the girl, Jane needed to see into both the character as she understood her from the literary text and the character as personified by her friend in the dance. 
Jane and Martha's emotional response to the characters illustrates the ways in which readers' personal characteristics and histories enable them to construct meaning for the signs of the text. The medium of dance provided them a forum for exploring and acting out their emotions through the characters they portrayed, and was enacted in a classroom environment that sanctioned both their empathic response to the story and their use of the choreographed medium through which to interpret it.

\section{Representing Meaning through Kinesthetic and Spatial Relations}

Jane and Martha reported that they represented their interpretation of the relationship between the characters through positioning, movement, and expression as they choreographed and performed their dance, illustrating Hanna's (1987) view of dance as semiotic activity. In so doing they drew on both spatial and bodily/ kinesthetic intelligences to express their interpretation. In discussing the quality and importance of spatial intelligence, Gardner (1983) identifies two properties that are relevant to the discussion of dance as a medium for representing meaning and shaping understanding. Spatial intelligence, he argues, involves (a) "the capacity to conjure up mental imagery and then to transform that imagery," resulting in the "metaphoric ability to discern similarities across diverse domains" (p. 176); and (b) the "more abstract and elusive" capacity to produce the "feelings of tension, balance, and composition [that] contribute to the power of a display, occupying the attention of artists and viewers of the arts" (p. 176). Dancers create the appropriate facets of composition through the spatial relations involved in choreography.

Spatial intelligence is often expressed in conjunction with what Gardner (1983) calls bodily/kinesthetic intelligence, which involves "the ability to use one's body in highly differentiated and skilled ways, for expressive as well as goal-directed purposes" (p. 206). In describing bodily/kinesthetic intelligence, Gardner challenges the Cartesian dichotomy between mind and body and its assumption that "what we do with our bodies is somehow less privileged, less special, than those problem-solving routines carried out chiefly through the use of language, logic, or some other relatively abstract symbolic system" (p. 208). In semiotic fashion, then, he argues that different symbol systems have similar potential for enabling people to construct and communicate meaning (cf. Hanna, 1987; Smagorinsky, 1995; Smagorinsky \& Coppock, 1994a, 1994b; Wertsch, 1991; Witte, 1992).

The following sections describe how Jane and Martha's dance involved the use of both spatial and bodily/kinesthetic intelligences in two areas: (a) visualizing images to inspire their performance and (b) representing characters through physical symbolization.

Visualizing images. Both Jane and Martha reported relying on the creation of mental images to help interpret and project their characters. Martha had difficulty performing some of the leaps required in the production and Jane told her to "pic- 
ture a pond that you're trying to jump over and she did." Jane further reported that she typically conjured up a mental image of an animal to help her interpret characters in dance:

Jane: In dance you talk with your body, not your mouth. You don't have to be anybody. It is kind of like a swan, you just aren't even anybody.

$Q$ : Well, what did you feel like when you were doing this dance? Did you feel like the character or did you feel like a swan?

Jane: Like a swan.

$Q: \quad$ Is that the animal that you always think about when you dance?

Jane: Ballet. When it is modern jazz, I feel like a cheetah.

Jane returned to the image of the swan on several occasions during the interview. She appeared to summon the image both to help herself perform and to strengthen her self-esteem: "I did feel like a swan because I could do those leaps and stuff and that makes you feel real graceful and the swans are real graceful. It made me feel pretty when I dance, so I still felt like a swan, but I felt the [doctor's] emotions too." Jane and Martha's ability to visualize images was critical to their ability to envision the form their dance would take, and it enhanced their ability to perform it. In that the form of the dance represented their interpretation of the story, their visualization informed their developing understanding of the relationship between the literary characters.

Representing characters through physical symbolization. In drawing parallels between the capacities to communicate through bodily/kinesthetic movement and other forms of intelligence, Gardner (1983) maintains that "mastery of such symbolic functions as representation (denoting an entity, like a person or an object) and expression (communicating a mood, like gaiety or tragedy) provides individuals with the option of mobilizing bodily capacities in order to communicate diverse messages" (p. 221). Planning and performing their dance required Jane and Martha to draw on related sets of abilities to represent their response to the characters.

Jane and Martha needed to depict the relationship between the characters through nonverbal movement. One key challenge they faced was how to represent the relationship between the characters spatially. Jane reported that "It was hard" to determine how they should do this. At the beginning of the story the doctor tries to appear nonthreatening to the girl in the hopes that she will consent to an examination. According to Jane:

You have to, it is like you are saying you have to put yourself in their position. When you read the story it tells, it is like in between the lines, it tells how the doctor feels about the girl, and it tells how the little girl feels. At the first of the dance we dragged, moved out, and we dragged out. It was like she was still closed out from the doctor, it was like he was feeling kind of depressed because he couldn't get into her and he knew she was dying. He had this idea in his head and he didn't want to believe it until he could prove it and he didn't want her to die because this would be the third kid that had died. 
As the story progressed and the girl began to resist, Jane and Martha changed the spatial relations from the "dragged" choreography to oppositional movement: "When the doctor is trying to get her around to his way of thinking, we figuratively did it by going around in circles opposite each other," recounted Jane. The idea of placing the characters in diametrical opposition and circling one another represented both the doctor's attempt to persuade and the girl's effort to evade.

Later in the dance the roles were reversed:

Martha: The way that we set the dance up, we were kind of going in circles and she was chasing me or I was chasing her, but the way we set it up she was chasing me. I was getting real scared, kind of had up my own little wall.

$Q: \quad$ You talked about the dancers being opposite to each other in your dance. What part of the story were you showing when the girl was chasing the doctor? Do you remember when that was?

Jane: When she was enraged, she was trying to get back at me.

Martha: That was the second time after we went down and came up again.

Toward the end of the dance Jane and Martha were faced with a different sort of spatial problem. According to Jane:

We did another dance at the very end and we were practicing on it and like she's sheltered like the little girl is hidden. She won't let anybody find out what her secret is and that's what she is doing. She is hiding and the doctor is trying to follow in her footsteps to try to figure out what is going on. And at the very end when it says that she did have [diphtheria], in the dance we made her die. She just fell and the doctor picked her up and carried her. Because like we were going to have the doctor die with her because it was like the third patient he had died and he was dying inside, but [our teacher] didn't really like that. And after we started thinking you know how he gets underneath the skin real hard, it is like we started thinking about it too and he doesn't really die. He tries to help her and stuff. We went further than the story went.

Here Jane and Martha attempted to represent the figurative death of the character by physically having her die. After their teacher's intervention they constructed another figurative representation of the story's ending, as described by Jane:

That is when they finally figured it out. It is like at the very end they walked together. It's like they walk two steps and when you do a little pause, the doctor shelters her and just looks at her because he's died with her. His whole life has just gone down the drain because it's another kid, he feels it's all his fault this time. And that is how I really felt when I was doing the dance.

Their representation of the story's denouement is quite different from the literal action of the story, where the girl attacks the doctor in a rage. Jane and Martha chose to represent the feelings of the doctor in their dance, however, and therefore focused on his sense of loss. Their depiction of the relationship between doctor and patient involved the creation of an alternative text world based on their shared 
understanding of the emotional state of the doctor, one that required them to recreate the literal action of the original text in order to represent their view of the emotional story line they developed through their infusion of the signs of the text with personal meaning. Jane and Martha's creation of an alternative reading illustrates the process Rosenblatt (1978) describes as "compenetration": "The reader brings to the text his past experience and present personality. Under the magnetism of the ordered symbols of the text, he marshals his resources and crystalizes out from the stuff of memory, thought, and feeling a new order, a new experience, which he sees as the poem" (p. 12). In this case that "new order" does not literally match the linguistic signs offered by Williams in his story, but instead represents a specific response to one character's emotional state interpreted through the emotional experiences of the dancers.

\section{Dialectic Function of Dance}

Our analysis thus far has centered on the extent to which Jane and Martha used the medium of dance to develop a representation of the characters and their relationship, and to reflect on the process of their transaction with the literary text to come to a better understanding of the story and of their own experiences that informed their response to it. As much of our analysis has revealed, the choreographed text itself was shaped by their thinking about the story. Martha's consideration of the feelings of the girl, for instance, determined how she would position herself spatially in relation to Jane in the role of the doctor.

Yet the interview also revealed that their thinking was shaped by the process of choreographing the dance. As related in the previous section, Jane and Martha tried several different endings to their interpretive dance. Through the teacher's intervention, they rejected one as insufficient in accounting for the characters' state of mind; through the process of reconsidering how to choreograph the final scene, they came to a more fully developed interpretation of the characters and their relationship. Their understanding of the story thus changed through their process of choreographing the dance.

Jane reported that she also experienced a change in her understanding of the doctor's perspective through her portrayal of him. When asked if she had learned anything new in the process of creating the dance, Jane replied:

Jane: I finally figured out what it is like to be in that position of the doctor. That is why I didn't hate the doctor so much because I knew how he felt and I also knew how the little kid felt and I felt sorry for the kid.

$Q: \quad$ Are those things you learned while doing the dance?

Jane: How the doctor felt. I knew his feelings, but knowing it and feeling it is totally different things.

Later in the interview she added, "[I learned] about myself, that I can feel their feelings. I see how they feel." In addition to experiencing the rational change in 
thought characteristic of semiotic mediation, Jane revealed that she also went through an emotional change as a result of her portrayal of the doctor.

The transforming effects of planning and performing the dance reveal a potential similar to that which some have ascribed to writing. In describing the shortcomings of conventional writing instruction, Applebee (1981) argues that writing only for the purpose of transmitting information does not enable students to employ:

writing as a tool for exploring a subject.... [W]riting can be a powerful process for discovering meaning rather than just transcribing an idea that is in some sense waiting fully developed in the writer's mind. Our language provides a whole panoply of devices that not only convey our meaning to others, but help us develop the meaning for ourselves. ... [W]e tend to overlook the extent to which these devices help us generate new ideas "at the point of utterance." (p. 100)

Applebee writes in the tradition of Vygotsky $(1978,1987)$, who stressed the role of speech as a psychological tool in mediating thought and activity. Viewed from this perspective, speech and writing serve reciprocal functions: to represent a person's thoughts and to develop those thoughts as well.

Jane and Martha's remarks reveal that the choreography and performance of their dance served the same dual purpose for them. The dance represented their understanding of the story and at the same time deepened their understanding of the characters they portrayed, which in turn enabled them to produce a more insightful interpretation. The dance thus served as a psychological tool to mediate their thought and activity, exhibiting the same properties typically attributed exclusively to writing (e.g., Emig, 1983) and other uses of language in promoting cognitive growth.

Enciso (1992) reports that in her research with young readers' evocations of stories, "the readers who were most involved in the stories they read were also more able to describe and discuss the events and implications of the story in greater depth and detail" (p. 99). The experience of Jane and Martha suggests that a reciprocal process can also take place: that a reader's exploration of events and implications of a story may cause greater involvement in the reading transaction.

\section{Mediating Function of the Social Context of Learning}

In the previous section we discussed the manner in which the psychological tool of dance mediated Jane and Martha's transaction with the literary text. Through the dance they also created a new interpretive text, that being the choreographed text in which they developed a new story line to depict the emotional state of the doctor.

We see the creation of this interpretive text as being facilitated by the social context of the classroom, and further by the social context of the stimulated recall interview. The classroom itself was located in an alternative school that stressed 
the importance of reflection and introspection, and that supported teaching approaches that engaged students in meaningful, productive work. As we reported previously, the social context of the classroom included a teacher who was predisposed to appreciate the arts and their potential for mediating thought and activity. Through the teacher's initiative the students had a wide range of communication genres available to them, thus enabling Jane and Martha to select a medium that was culturally appropriate to their personal and collective histories.

In addition to the broad social context of the classroom, Jane and Martha's choreographed interpretation was mediated by their interaction with one another and by the brief intervention of their teacher. As the transcripts reported thus far reveal, Jane and Martha discussed and explored a number of possible ways to interpret the story. Their collaboration involved a mutual construction of the story's meaning and a discussion of how to represent that meaning. Although Jane played a leading role in developing the choreography due to her greater experience and expertise in dance and her dominant role in their friendship, their process of interpreting the story was collaborative, with each student's personal experiences providing the basis for the portrayal of the two characters.

Their teacher's intervention contributed an additional voice to their consideration of how to represent the relationship between the girl and the doctor. As noted, Jane and Martha generated one possible ending to the story but when they suggested it to their teacher he raised a question which caused them to reconsider their interpretation. The role of the teacher in directing the students' thinking thus served as an additional mediating factor in the development of the interpretive text.

Finally, as we discussed in the section on research method, the stimulated recall interview itself could have caused a further development of the interpretation of the story. The interview took place the day after the choreography of the dance, within the 2-day range of data collection recommended by Bloom (1954) and Greene and Higgins (1994). The period between the choreography and the interview undoubtedly involved some reconsideration of both the story and the dance, and the interview could well have provided the scaffolding for ordering that new interpretation (cf. Smagorinsky, in press; Swanson-Owens \& Newell, 1994). We see, then, a series of mediating factors that aided Jane and Martha in the development of their interpretive text, a process that no doubt continued beyond the confines of the data collection.

\section{DISCUSSION}

Our analysis of Jane and Martha's literary transaction looks at the dynamic interplay of reader, text, and context in the construction of meaning, illustrating the processes involved when reading and meaning construction are viewed as semiotic activities. In literary response the text provides the blueprint for readers to 
use to draw on their own personal and cultural histories in the construction of meaning through text forms encouraged by the particular communication genres available within a given sociocultural setting. In the substance abuse treatment center Jane and Martha were not only enabled to construct an interpretive text that emerged from their personal transaction with the characters in the story, they were enabled to do so within a broad communication genre that allowed them to use cultural tools with which they were uniquely dexterous.

The study illustrates McGinley and Tierney's (1989) contention that "students' self-directed engagements in reading and writing to learn" (p. 245) are critical to learning. They argue that "the ability to direct dynamically one's own reading and writing engagements in order to learn is central to conducting [a critical examination of a topic] by virtue of the diverse, situationally appropriate combinations and perspectives that self-direction permits" (p. 250). Our own investigation points to the potential for engagement and learning when students direct not only their means of writing engagement but their medium of interpretation. Many theorists have maintained that "Writing represents a unique mode of learning-not merely valuable, not merely special, but unique" (Emig, 1983, p. 123). The research we report supports the notion that other forms of response have similar potential for promoting learning to that generally ascribed exclusively to writing, depending on the extent to which the psychological tools are valued in the setting.

We make these points keeping in mind the unique learning environment of the substance abuse treatment center. Jane and Martha's milieu included the approval of a range of communication genres, the teacher's background in the arts, the teacher's educational experiences, an emphasis on introspection in their therapy, Jane's experience with dance, and other factors that contributed to the acceptance of choreography as a legitimate means of mediating a response to literature. We see Jane and Martha's response to the literary work as necessarily tied to the context of their production. The "tool kit" of response media available to them was institutionally valued in ways that by most accounts (e.g., Goodlad, 1984; Sizer, 1987) are not appreciated in most educational settings.

We would be mistaken, then, to use this research to suggest the broadening of response media in mainstream schools unless such a change is part of a larger rethinking of the communication genres valued and available in classrooms. The use of dance (and other artistic means of response) in the case we have reported is embedded in a larger set of values that focuses on the students' construction of meaning rather than the particular forms that meaning construction may take. Ackerman (1993) has criticized proponents of "writing to learn" activates for crediting great changes in student performance to specific instructional methods without considering that "classroom change on the order implied ... happens in the midst of a multidimensional restructuring" in assumptions, philosophy, theory, authority, sequencing, and administrative support (p. 345). The experience of Jane and Martha suggests that in a social context that supports the construction of per- 
sonally meaningful texts, students can draw on a variety of personal understandings to build meaningful interpretations of literature. To develop their understandings, however, the tools they use must be valued in the instructional setting.

\section{REFERENCES}

Ackerman, J. (1993). The promise of writing to learn. Written Communication, 10, 334-370.

Applebee, A. N. (1981). Writing in the secondary school: English and the content areas (NCTE Research Report No. 21). Urbana, IL: National Council of Teachers of English.

Applebee, A. N. (1993). Literature in the secondary school: Studies of curriculum and instruction in the United States (NCTE Research Report No. 25). Urbana, IL: National Council of Teachers of English.

Bakhtin, M. M. (1986). Speech genres and other late essays (C. Emerson \& M. Holquist, Eds.; V. W. McGee, Trans.). Austin: University of Texas Press.

Beach, R. (1993). A teacher's introduction to reader-response theories. Urbana, IL: National Council of Teachers of English.

Bloom, B. (1954). The thought process of students in discussion. In S. J. French (Ed.), Accent on teaching: Experiments in general education (pp. 23-46). New York: Harper.

Bloome, D., \& Bailey, F. M. (1992). Studying language and literacy through events, particularity, and intertextuality. In R. Beach, J. L. Green, M. L. Kamil, \& T. Shanahan (Eds.), Multidisciplinary perspectives on literacy research (pp. 181-210). Urbana, IL: National Conference on Research in English and National Council of Teachers of English.

Chin, E. (1994). Redefining "context" in research on writing. Written Communication, 11, 445-481.

Csikszentmihalyi, M., \& Larson, R. (1984). Being adolescent: Growth and conflict in the teenage years. New York: Basic Books.

DiPardo, A. (1994). Stimulated recall in research on writing: An antidote to "I don't know, it was fine." In P. Smagorinsky (Ed.), Speaking about writing: Reflections on research methodology (pp. 163-181). Thousand Oaks, CA: Sage.

Enciso, P. (1992). Creating the story world: A case study of a young reader's engagement strategies and stances. In J. Many \& C. Cox (Eds.), Reader stance and literary understanding: Exploring the theories, research, and practice (pp. 75-102). Norwood, NJ: Ablex.

Emig, J. (1983). Writing as a mode of learning. In D. Goswami \& M. Butler (Eds.), The web of meaning: Essays on writing, teaching, leaming, and thinking (pp. 122-131). Upper Montclair, NJ: Boynton/ Cook.

Gardner, H. (1983). Frames of mind: The theory of multiple intelligences. New York: Basic Books.

Gardner, H. (1993). The theory of multiple intelligences: Theory into practice. New York: Basic Books.

Goodlad, J. I. (1984). A place called school: Prospects for the future. New York: McGraw-Hill.

Greene, S., \& Higgins, L. (1994). "Once upon a time": The use of retrospective accounts in building theory in composition. In P. Smagorinsky (Ed.), Speaking about writing: Reflections on research methodology (pp. 115-140). Thousand Oaks, CA: Sage.

Hancock, M. R. (1993). Exploring the meaning-making process through the content of literature response journals: A case study investigation. Research in the Teaching of English, 27, 335-368.

Hanna, J. L. (1987). To dance is human: A theory of nonverbal communication. Chicago: University of Chicago Press.

Harste, J. C. (1993, December). Multiple ways of knowing: Curriculum in a new key. Paper presented at the meeting of the National Reading Conference, Charleston, SC.

Hull, G., \& Rose, M. (1990). "This wooden shack place": The logic of an unconventional reading. College Composition and Communication, 41, 287-298.

Lemke, J. (1988). Genres, semantics, and classroom education. Linguistics and Education, 1, 81-99. 
Marshall, J. D., Smagorinsky, P., \& Smith, M. W. (1995). The language of interpretation: Pattems of discourse in discussions of literature (NCTE Research Report No. 27). Urbana, IL: National Council of Teachers of English.

McGinley, W., \& Tierney, R. J. (1989). Traversing the topical landscape: Reading and writing as ways of knowing. Written Communication, 6, 243-269.

Moll, L. C. (1990). (Ed.). Vygotsky and education: Instructional implications and applications of saciohistorical psychology. New York: Cambridge University Press.

Nystrand, M. (1986). The structure of written communication: Studies in reciprocity between writers and readers. Orlando and London: Academic Press.

Nystrand, M. (1989). A social-interactive model of writing. Written Communication, 6, 66-85.

Nystrand, M., Greene, S., \& Wiemelt, J. (1993). Where did composition studies come from? An intellectual history. Written Communication, 10, 267-333.

Olson, D. R. (1977). From utterance to text: The bias of language in speech and writing. Harvard Educational Review, 47, 257-281.

Peirce, C. S. (1931-1935). Collected papers of Charles Sanders Peirce (Vols. 1-6) (C. Hartshorne \& P. Weiss, Eds.). Cambridge, MA: Harvard University Press.

Rose, M. (1984). Writer's block: The cognitive dimension. Carbondale: Southern Illinois University Press.

Rosenblatt, L. M. (1978). The reader, the text, the poem: The transactional theory of the literary work. Carbondale: Southern Illinois University Press.

Rosenthal, R. (1966). Experimenter effects in behavioral research. New York: Appleton-Century-Crofts.

Sizer, T. R. (1987). Horace's compromise: The dilemma of the American high school, Boston: Houghton Mifflin.

Smagorinsky, P. (1986). An apology for structured composition instruction. Written Communication, 3 , $105-122$.

Smagorinsky, P. (1991). Expressions: Multiple intelligences in the English class. Urbana, IL: National Council of Teachers of English.

Smagorinsky, P. (1992). Reconfiguring the English class through multiple intelligences. In J. Collins (Ed.), Vital Signs 3: Restructuring the English class (pp. 35-44). Portsmouth, NH: Heinemann Boynton/ Cook.

Smagorinsky, P. (1994). Think-aloud protocol analysis: Beyond the black box. In P. Smagorinsky (Ed.), Speaking about writing: Reflections on research methodology (pp. 3-19). Thousand Oaks, CA: Sage.

Smagorinsky, P. (1995). Constructing meaning in the disciplines: Reconceptualizing Writing Across the Curriculum as Composing Across the Curriculum. American Journal of Education, 103, 160-184.

Smagorinsky, P. (in press). The social construction of data: Methodological problems of investigating learning in the zone of proximal development. Review of Educational Research.

Smagorinsky, P., \& Coppock, J. (1994a). Cultural tools and the classroom context: An exploration of an artistic response to literature. Written Communication, 11, 283-310.

Smagorinsky, P., \& Coppock, J. (1994b). Exploring artistic response to literature. In C. K. Kinzer \& D. J. Leu (Eds.), Multidisciplinary aspects of literacy research, theory, and practice. Forty-third yearbook of the National Reading Conference (pp. 335-341). Chicago: National Reading Conference.

Smagorinsky, P., \& Coppock, J. (in press), Reading through the lines: An exploration of a dramatic response to literature. Reading and Writing Quarterly.

Smagorinsky, P., \& Fly, P. K. (1993). The social climate of the classroom: A Vygotskian perspective on small group process. Communication Education, 42, 159-171.

Suhor, C. (1984). Towards a semiotics-based curriculum. Journal of Curriculum Studies, 16, 247-257.

Swanson-Owens, D., \& Newell, G. E. (1994). Using intervention protocols to study the effects of instructional scaffolding on writing and learning. In P. Smagorinsky (Ed.), Speaking about writing: Reflections on research methodology (pp. 141-162). Thousand Oaks, CA: Sage.

Vygotsky, L. S. (1934). Myshlenie i rech': Psikhologicheskie issledovaniya [Thinking and speech: Psychological investigations]. Moscow and Leningrad: Gosudarstvennoe Sotsial'no-Ekonomicheskio Izdatel'stvo. 
Vygotsky, L. S. (1978). Mind in society: The development of higher psychological processes (M. Cole, V. John-Steiner, S. Scribner, \& E. Souberman, Eds.). Cambridge, MA: Harvard University Press.

Vygotsky, L. S. (1987). Thinking and speech. In L. S. Vygotsky, Collected works (R. Rieber \& A. Carton, Eds; N. Minick, Trans.) (Vol. 1, pp. 39-285). New York: Plenum.

Wertsch, J. V. (1985). Kygotsky and the social formation of mind. Cambridge, MA: Harvard University Press.

Wertsch, J. V. (1990). The voice of rationality in a sociocultural approach to mind. In. L. C. Moll (Ed.), Vygotsky and education: Instructional implications and applications of sociohistorical psychology (pp. 111-126). New York: Cambridge University Press.

Wertsch, J. V. (1991). Voices of the mind: A sociocultural approach to mediated action. Cambridge, MA: Harvard University Press.

Witte, S. P. (1992). Context, text, intertext: Toward a constructivist semiotic of writing. Written Communication, 9, 237-308.

Zinchenko, V. P. (1985). Vygotsky's ideas about units for the analysis of mind. In J. V. Wertsch (Ed.), Culture, communication, and cognition: Vygotskian perspectives (pp. 94-118). New York: Cambridge University Press.

\section{AUTHOR NOTE}

This research was supported by a Junior Faculty Summer Research Fellowship from the University of Oklahoma. We would like to thank Pat Enciso, Stuart Greene, Susan Laird, Michael W. Smith, and Norm Unrau, as well as the editors and external reviewers of $J R B$, for their perceptive responses to earlier drafts of this manuscript.

Manuscript received: January 19, 1994

Revision requested: April 1, 1994

Revision received: May 20, 1994

Accepted for publication: October 28, 1994 